\section{Integration of IGF, FGF, and anti-BMP signals via Smad1 phosphorylation in neural induction}

\author{
Edgar M. Pera, ${ }^{1}$ Atsushi Ikeda, Edward Eivers, and \\ Eddy M. De Robertis ${ }^{2}$ \\ Howard Hughes Medical Institute and Department of \\ Biological Chemistry, University of California, Los Angeles, \\ Los Angeles, California 90095-1662, USA
}

How do very diverse signaling pathways induce neural differentiation in Xenopus? Anti-BMP (Chordin), FGF8, and IGF2 signals are integrated in the embryo via the regulation of Smad1 phosphorylation. Neural induction results from the combined inhibition of $B M P$ receptor serine/threonine kinases and activation of receptor tyrosine kinases that signal through MAPK and phosphorylate Smad1 in the linker region, further inhibiting Smad1 transcriptional activity. This hard-wired molecular mechanism at the level of the Smad1 transcription factor may help explain the opposing activities of IGF, FGF, and $B M P$ signals not only in neural induction, but also in other aspects of vertebrate development.

Received September 18, 2003; revised version accepted October 24, 2003.

A central question in biology is how a small number of cell-cell signaling pathways are integrated during development, leading to the differentiation of many cell types. The induction of the central nervous system (CNS) has been a primary focus of embryological research for many years (Spemann 1938; Harland 2000; Wilson and Edlund 2001; Stern 2002). In Xenopus, bone morphogenetic protein (BMP) antagonists such as Noggin, Chordin, and Follistatin inhibit signaling by BMP receptors, causing neural induction through a default pathway (Weinstein and Hemmati-Brivanlou 1999; De Robertis et al. 2000). However, active signals such as fibroblast growth factors (FGFs) and insulin-like growth factors (IGFs) are also potent neural inducers (Hongo et al. 1999; Hardcastle et al. 2000; Streit et al. 2000; Wilson et al. 2000; Pera et al. 2001; RichardParpaillon et al. 2002). Here we show that Chordin, FGF8, and IGF2 have similar phenotypic effects on CNS development and synergize with each other. In loss-of-function experiments, FGF and IGF signaling are required for neurogenesis by Chordin. Microinjection of phosphorylation-deficient mutants of Smad1 suggests that antagonism of BMP receptor activity is not the sole regulator of neural induction in the embryo. In Xenopus,

[Keywords: IGF, FGF, BMP, Smad, Chordin, neural induction, Xenopus] ${ }^{1}$ Present address: Institut für Biochemie und Molekulare Zellbiologie, Abteilung Entwicklungsbiochemie, Georg August Universität Göttingen, Justus-von-Liebig-Weg 11, 37077 Göttingen, Germany.

${ }^{2}$ Corresponding author.

E-MAIL derobert@hhmi.ucla.edu; FAX (310) 206-2008.

Article and publication are at http://www.genesdev.org/cgi/doi/10.1101/ gad.1153603.
FGF8 and IGF2 induce phosphorylation of the linker region of Smad1 via mitogen-activated protein kinase (MAPK), which further inhibits Smad1 activity (Kretzschmar et al. 1997). The results suggest a common molecular mechanism for the action of diverse neural inducers in vertebrate development, in which multiple signaling inputs lead to inhibition of the BMP pathway through the regulation of Smad phosphorylation.

\section{Results and Discussion}

The unexpected finding that IGF mRNA can induce neural differentiation (Pera et al. 2001) prompted us to compare the phenotypic effects of various neural inducers. First we compared the effects of the BMP antagonist Chordin (Chd), IGF2, or FGF8 on neural plate formation. Careful titration of microinjected mRNAs revealed that each agent was able to expand the neural plate (Fig. 1AD). At lower doses, Chd, IGF2, and FGF8 induced ectopic sensory neurons, marked by $N$-tubulin, in the epidermis (Fig. 1E-H). Interestingly, genetic studies in zebrafish have shown that differentiation of these lateral-most sensory neurons is controlled by a gradient of BMP signals in the ectoderm (Nguyen et al. 2000).

To determine whether these signaling pathways synergized in vivo, we microinjected recombinant proteins into the blastocoele cavity of the embryo (Fig. 1I-P; Cooke and Smith 1989). Co-injection of Chd and IGF2 proteins cooperated, leading to dorsalized embryos with large cement glands, shortened axes, and expanded dorso-anterior structures (Fig. 1L). A synergism was also observed between Chd and FGF8, resulting in the induction of abundant ectopic neurons in the epidermis (Fig. 1P). Although IGF2 and FGF8 have similar effects, we noted differences as well. IGF2 induces prominent eye and cement gland structures (Pera et al. 2001), whereas FGF8 induces massive neurogenesis in the absence of eye and cement gland differentiation (Fig. 1I-P; Christen and Slack 1997; Hardcastle et al. 2000). Thus, although the effects on neural induction showed strong parallels, FGF8 and IGF2 appear to regulate cell fate by other mechanisms as well. All three signaling pathways were required for neurogenesis (Fig. 1Q-S), as the differentiation of primary neurons was inhibited by BMP7 mRNA (which counteracts Chd), by an IGF receptor antisense morpholino oligo (IGFR-MO, Richard-Parpaillon et al. 2002), or by dominant-negative FGF receptor $4 a$ mRNA (DN-FGFR4a; Hongo et al. 1999).

Taken together, the results suggested that strong parallels existed between the effects of the BMP antagonist Chd, IGF2, and FGF8 in neural induction (Fig. 1T). In gain-of-function experiments, similar phenotypes were obtained with the three agents, and the microinjected proteins synergized. In loss-of-function studies, the IGF and FGF pathways were found to be required for neurogenesis. Remarkably, neural induction by Chd mRNA in the well established animal cap explant assay also required intact IGF and FGF signaling pathways (Fig. 1U, lanes 3-6). Although Chordin is a very potent neural inducer, it does not work in the absence of IGF or FGF signaling. These intriguing relationships between such different neural inducing pathways prompted us to investigate whether a common molecular explanation could be found. 

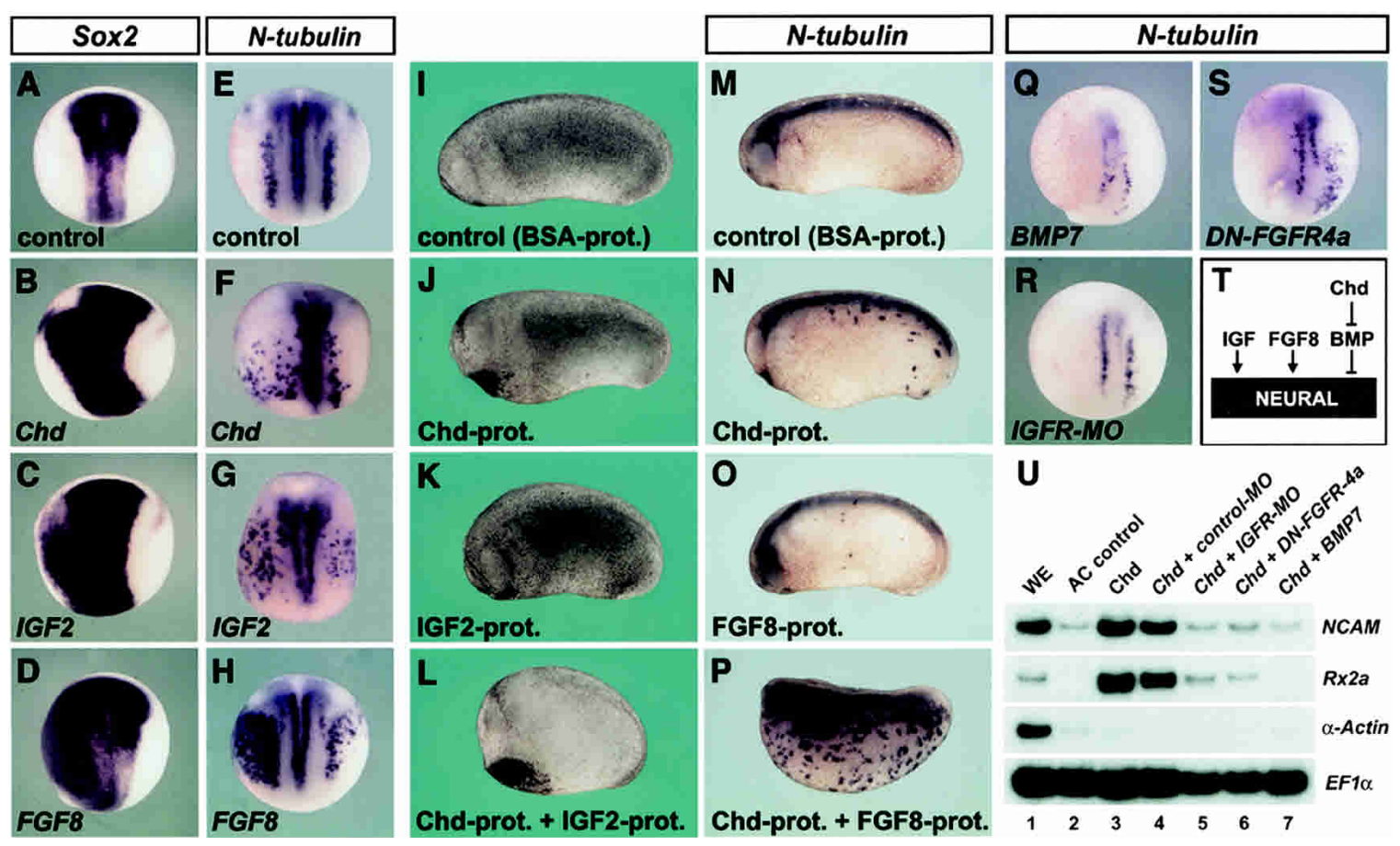

Figure 1. Comparison of neural induction by Chordin, IGF, and FGF8 in Xenopus embryos. $(A-D)$ Sox2 expression: Microinjection of Chd (10 pg), IGF2 (800 pg), or FGF8 (50 pg) mRNA into a single animal blastomere at the 4-8-cell stage expanded the neural plate on the injected side. (E-H) N-tubulin expression: Chd (4 pg), IGF2 (100 pg), or FGF8 (5 pg) mRNA expanded the lateral-most sensory neurons (Rohon-Beard neurons) into lateral epidermis. (I-P) Embryos injected with protein into the blastocoele at blastula stage. Protein amounts per injection were $2.6 \mathrm{ng}$ Chordin, 2 ng IGF2, and 1.4 ng FGF8, injected together with 40 ng BSA. $(I-L)$ Unstained tail bud-stage embryos. $(M-P)$ In situ hybridization for $N$-tubulin. (Q-S) Loss of N-tubulin-positive neurons after a single animal injection of $250 \mathrm{pg} B M P 7 \mathrm{mRNA}, 16 \mathrm{ng}$ IGFR-MO, or 500 pg $D N-F G F R 4 a$ mRNA at the 4-cell stage. (T) Summary of signals involved in neural induction. (U) Animal cap explants from embryos injected with Chd mRNA (4 pg/blastomere) alone or in combination with control-MO (16 ng), IGFR-MO (16 ng), DN-FGFR4a mRNA (500 pg), or BMP7 mRNA $(250 \mathrm{pg})$. Frequency of embryos with the indicated phenotypes was: $B, 34 / 35 ; C, 27 / 32 ; D, 16 / 19 ; F, 14 / 22 ; G, 37 / 51 ; H, 117 / 120 ; Q$, $26 / 30 ; R, 41 / 47 ; S, 34 / 38$; (U) 10 explants per lane (tail bud stage), three independent experiments.

An important effector of BMP signals is the transcription factor Smad1, which becomes phosphorylated at three conserved carboxy-terminal serine residues upon activation by the BMP receptor (BMPR) serine/threonine kinase (Massagué and Chen 2000). In pioneering work, Kretzschmar et al. (1997) showed that Smad1 also undergoes phosphorylation by MAPK in the central linker region (Fig. 2B). Whereas phosphorylation by BMPR promotes nuclear translocation and transcriptional activity of Smad1, phosphorylation by MAPK in the linker region has the opposite effect, causing cytoplasmic localization and inhibition of transcriptional activity (Kretzschmar et al. 1997; Massagué and Chen 2000). These opposing effects were discovered in tissue culture cell lines treated with epidermal growth factor (EGF) or hepatocyte growth factor (HGF), which signal through receptor tyrosine kinases (RTKs) and activate the extracellular signal-regulated kinase (Erk)/MAPK pathway (Kretzschmar et al. 1997). However, the relevance of this MAPK phosphorylation to physiological processes remained to be determined.

Whether the Kretzschmar et al. (1997) paradigm functions in vivo is an important question in cell-cell signaling. This is because these interactions between the EGF and BMP pathways would be hard-wired at the level of Smad1 transcription factor activity. A more flexible way of regulating transcription factor activity is for different pathways to act on separate transcription factors that interact through independent binding sites in individual target gene promoters. MAPK sites have also been identified in the linker region of Smad2 (Kretzschmar et al. 1999), and a role for these sites in the loss of competence for mesoderm induction by Activin has been reported in Xenopus (Grimm and Gurdon 2002). However, the signaling pathway responsible for this phosphorylation has not been identified (Grimm and Gurdon 2002).

The potent neural inducing activity of FGF8 and IGF2 allowed us to investigate in vivo how these signaling pathways interact with the BMP pathway. FGF and IGF signal through RTKs that can activate the Erk/MAPK pathway (Blume-Jensen and Hunter 2001). Using the approach of Kretzschmar et al. (1997), we compared the phenotypic effects of Smadl constructs encoding wildtype (WT) or phosphorylation-insensitive mutant proteins in which the BMPR or MAPK target serines were substituted by alanine residues (Fig. 2B). Microinjection of WT-Smad1 mRNA into the animal pole of Xenopus embryos at the four-cell stage resulted in an unexpectedly mild ventralization phenotype, with slightly reduced head structures, a modest increase in ventral mesoderm marked by Sizzled expression (Fig. 2D,G; Collavin and Kirschner 2003), and a small decrease in CNS neurons marked by $N$-tubulin (Fig. 2E,H). The linker mutant LMSmad1 (Fig. 2B) has point mutations in the four MAPK phosphorylation sites (designated 4SP/AP in Kretzschmar et al. 1997). Microinjection of LM-Smad1 mRNA resulted in strongly ventralized phenotypes; embryos lacked head structures and most of the CNS (Fig. 2K), 

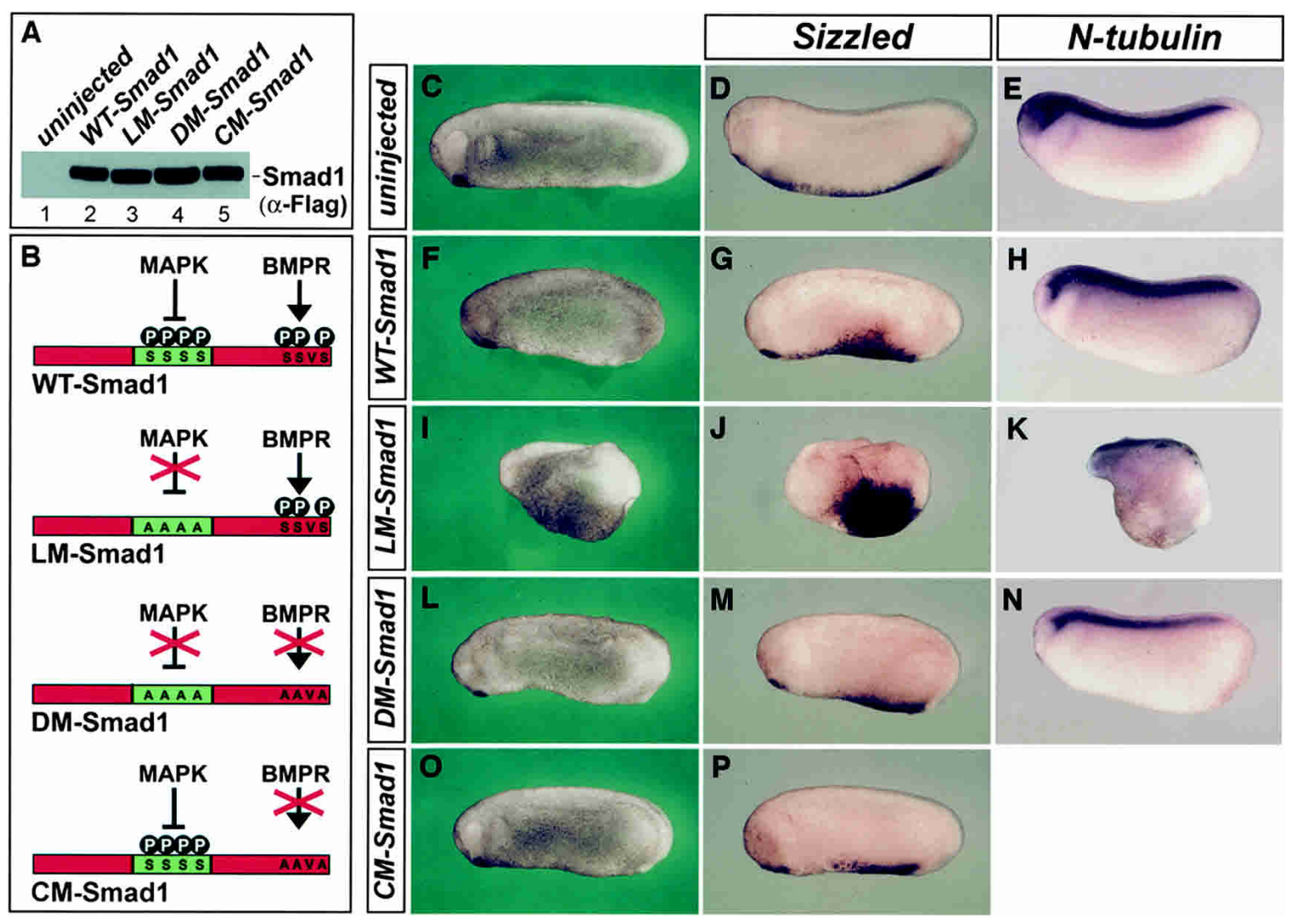

Figure 2. Endogenous embryonic MAPK signals inhibit Smadl activity in the Xenopus embryo. Wild type (WT), linker mutant (LM), double mutant $(D M)$, or carboxy-terminal mutant (CM) Smad1 mRNAs were injected into each blastomere at the 4-cell stage (250 pg per injection). $(A)$ Western blot showing similar levels of expression of Smadl proteins at gastrula stage. $(B)$ Diagram of Smadl mutant proteins. $(C-P)$ Uninjected and injected tail bud-stage embryos, unlabeled or after in situ hybridization with the ventral mesoderm marker Sizzled or the neuronal marker $N$-tubulin. Note that $L M$-Smad1 $(I, J, K)$ is very active in inhibiting CNS differentiation and expanding ventral tissue. A minimum of 30 embryos were used per injected sample, 10 independent experiments.

and had an expanded ventral mesodermal domain (Fig. 2J). These differences in activity were not caused by differences in levels of Smad1 protein expression (Fig. 2A). This strong Smadl ventralizing (pro-BMP) activity required both inactivation of the MAPK phosphorylation sites and active phosphorylation by BMPR. This can be inferred from the mild phenotype of the double mutant DM-Smad1, in which both the MAPK and the BMPR phosphorylation sites were inactivated (Fig. 2L-N). A construct having mutations in the carboxy-terminal sites only, CM-Smad1, had weak, if any, effects (Fig. 2O,P). The striking difference between the effects of WT-Smad1 and LM-Smad1 mRNA (Fig. 2, cf. $\mathrm{H}$ and $\mathrm{K}$ ) indicates that endogenous MAPK signals are able to antagonize Smad1 activity in the developing Xenopus embryo.

The observation that MAPK phosphorylation can inhibit WT-Smadl activity in vivo was further analyzed in a variety of neural induction assays (Fig. 3). The MAPKinsensitive LM-Smad1 was a much stronger inhibitor of neural plate (Sox2) and neuronal (N-tubulin) markers (Fig. 3C,G) than either WT-Smadl (Fig. 3B,F) or DMSmad1 (Fig. 3D,H). LM-Smad1 inhibited the ectopic neural induction caused by microinjection of FGF8 or IGF2 mRNAs in a cell-autonomous way (Fig. 3L,P), whereas WT-Smad1 mRNA had little or no effect (Fig. 3K,O). In cells co-injected with WT-Smad1 together with FGF8 or IGF2, MAPK levels should be high, preventing the antineural effects of Smadl shown in Figure 3K,O, which become evident only when MAPK phosphorylation is prevented in the LM-Smad1 mutant (Fig. 3L,P). In animal cap explants, injected Chd, FGF8, and IGF2 mRNAs had remarkably similar effects on gene expression (Fig. 3Q). They caused induction of anterior $(\operatorname{Otx} 2, \operatorname{Six} 3)$ but not posterior (Krox20, HoxB9) neural markers, and suppressed epidermal genes (Cytokeratin, Msx1, Vent2) in the absence of mesoderm ( $\alpha$-Actin, $\alpha$-Globin) induction (Fig. 3Q, cf. lanes 2,3,6,9). We note that although other FGFs induce the formation of mesoderm, which posteriorizes neural tissue (Lamb and Harland 1995), FGF8 suppresses mesoderm (Hardcastle et al. 2000), leading to the differentiation of predominantly anterior neural tissue in animal cap explants. Neural induction by Chd, FGF8, and IGF2 in animal cap explants was inhibited, and epidermal differentiation promoted, by co-injection of LM-Smad1 (Fig. 3Q, lanes 5,8,11). Overexpression of WT-Smad1 also inhibited neural differentiation (Fig. 3Q, lanes $4,7,10)$, but to a lesser degree. Taken together, these experiments indicate that phosphorylation by MAPK in the linker region of Smadl promotes neural induction. When this phosphorylation is prevented, Smad1 becomes a potent antineural agent.

To test whether FGF8 and IGF induce phosphorylation of Smadl in vivo, we used a gel mobility shift assay at low bisacrylamide concentrations to separate phosphorylated proteins (Chesnel et al. 1997). In NIH3T3 cells, addition of FGF8 protein for 10 min led to phosphoryla- 

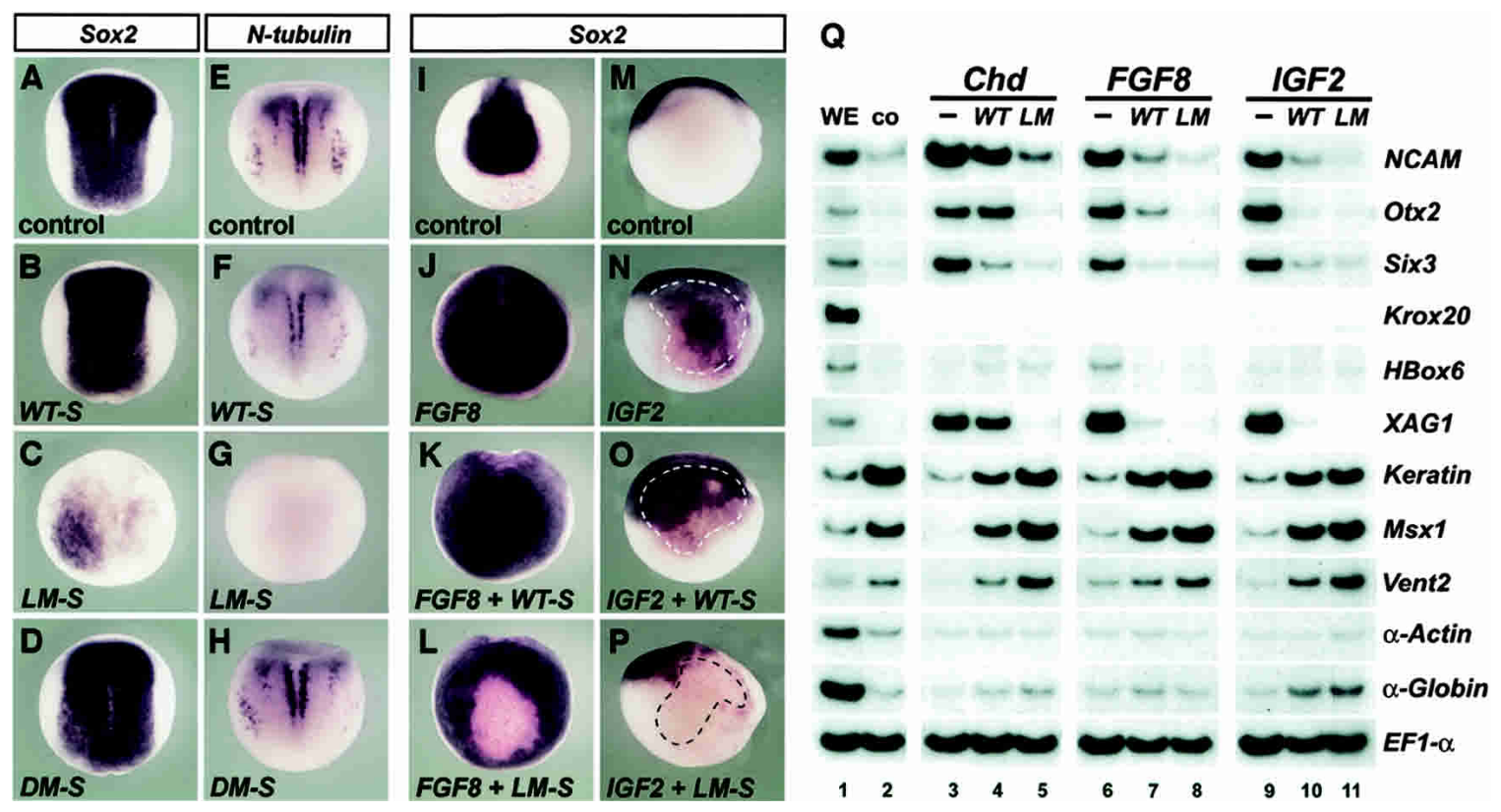

Figure 3. The MAPK phosphorylation mutant LM-Smad1 inhibits endogenous CNS formation and neural induction by FGF8 or IGF2 signals. $(A-H)$ Neurula-stage embryos in dorsal view, uninjected (control) or injected four times into the animal pole with WT-Smad1, LM-Smad1, or $D M$-Smad1 mRNA. (I-L) FGF8-injected embryos in anterior view. $(M-P) I G F 2$-injected embryos in lateral view. Embryos were injected at the 8-cell stage into a single animal blastomere together with nuclear lacZ mRNA as lineage tracer and stained for Sox2. Stippled lines mark the lacZ-positive injection sites. Note that LM-Smad1, but not WT-Smad1, blocks neural induction by FGF8 or IGF2 mRNA. (Q) RT-PCR analysis of stage 26 ectodermal explants from embryos injected at the 8-cell stage with the indicated mRNAs. WE, whole embryo; Co, uninjected animal cap explants used as controls. The amounts of injected mRNAs per blastomere were $250 \mathrm{pg}$ Smad1, $4 \mathrm{pg} C h d, 100 \mathrm{pg} F G F 8,800 \mathrm{pg} I G F 2$, and $200 \mathrm{pg}$ nuclear lacZ. Endogenous neural marker expression was inhibited in: $A, 0 / 72 ; B, 0 / 46 ; C, 58 / 58 ; D, 0 / 35 ; E, 0 / 44 ; F, 37 / 78 ; G, 67 / 68 ; H$, $9 / 23$ embryos. Ectopic Sox2 expression was inhibited in: $J, 0 / 23 ; K, 0 / 34 ; L, 24 / 32 ; N, 0 / 69 ; O, 0 / 53 ; P, 91 / 109$ embryos. In (Q) one whole embryo or 10 animal caps were used per lane, two independent experiments.

tion of endogenous Erk1 and Erk2 and of transfected WTSmad1 (Fig. 4A, lanes 1-4). The shift in Smad1 mobility was dependent on phosphorylation by MAPK, as it was not detected in LM-Smad1 (Fig. 4A, lanes 5,6). These phosphorylations required the MEK/Erk pathway, because the MEK inhibitor U0126 (Promega) blocked both Erk1/2 and Smad1 phosphorylation (Fig. 4B, lanes 3,4). Incorporation of radioactive orthophosphate into Smad1 proteins in mRNA-injected Xenopus embryonic cells confirmed that the linker MAPK sites are indeed phosphorylated (Fig. 4C). In developing Xenopus embryos at the blastula stage, microinjection of FGF8 protein into the blastocoele caused a mobility shift of Flag-tagged WT-Smad1, but not of LM-Smad1 (Fig. 4D, lanes 3,5). When IGF2 protein was tested in a similar manner, significant Erk2 phosphorylation in embryos was not detected (data not shown), perhaps owing to low levels of IGF receptor at blastula (Richard-Parpaillon et al. 2002). We therefore turned to Xenopus oocytes, which have a robust MAPK response to Insulin and IGF signals (Chesnel et al. 1997). Addition of IGF2 protein to the culture medium of oocytes previously microinjected with WTSmad1 mRNA induced phosphorylation of the linker region of WT-Smad1 (Fig. 4E). We conclude from these experiments that FGF8 and IGF2 can induce phosphorylation of Smad1 via the MEK/Erk MAPK pathway in vivo. Endogenous MAPK signals were also able to phosphorylate the Smad1 linker region. As shown in Figure 4F, WT-Smad1 but not LM-Smad1 was phosphorylated in early gastrula (stage 10.5) and late gastrula (stage 12.5) Xenopus embryos. The onset of this linker Smad1 phosphorylation by MAPK correlated well with the detection of activated phospho-Erk (Fig. 4F), suggesting that endogenous Erk signaling may cause the linker phosphorylation of Smadl in the Xenopus gastrula.

The results presented here suggest a unified molecular mechanism that can explain neural induction in Xenopus by multiple signals through inhibition of the BMP pathway at the level of Smadl phosphorylation (Fig. 5). BMP antagonists such as Chordin and Noggin prevent the phosphorylation of carboxy-terminal serines in Smad1, so that Smad1 is less active in inhibiting neural differentiation (Weinstein and Hemmati-Brivanlou 1999; De Robertis et al. 2000). FGF8 and IGF2 trigger phosphorylation of the Smad1 linker region by MAPK (the present study), further inhibiting Smad1 transcriptional activity (Kretzschmar et al. 1997) and thus promoting neurogenesis. This molecular mechanism may also help explain neural induction by HGF (Streit et al. 1995, 1997), which can induce Smad1 linker phosphorylation in cultured cells (Kretzschmar et al. 1997). Linker phosphorylation of $S m a d 2 / 3$ has also been shown to negatively control TGF- $\beta$ action (Kretzschmar et al. 1999; Grimm and Gurdon 2002). It is not known whether Smad2/3 phosphorylation has a role in neural induction, but we note that Smad2 is not active (that is, not phosphorylated at the carboxy-terminus) in Xenopus ectoderm (Schohl and Fagotto 2002). Thus, MAPK activity in ectoderm may not affect neural induction via Smad2/3, but rather decrease the competence for mesoderm induction by TGF- $\beta$ signals (Grimm and Gurdon 2002).

The finding that microinjected WT-Smad1 is unable to antagonize neural development in the presence of endogenous levels of MAPK signals (Figs. 2H, 3B) has impor- 
A

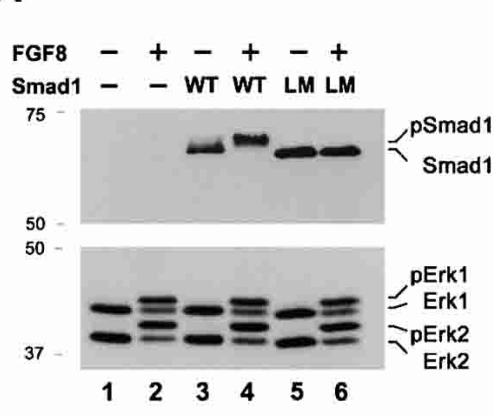

D

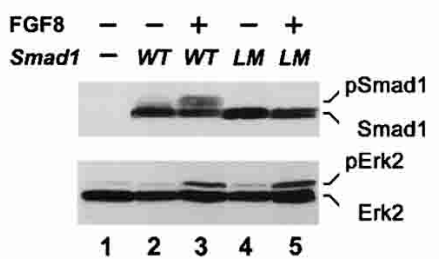

B

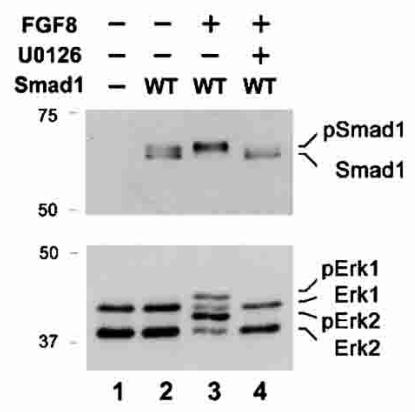

$\mathbf{E}$

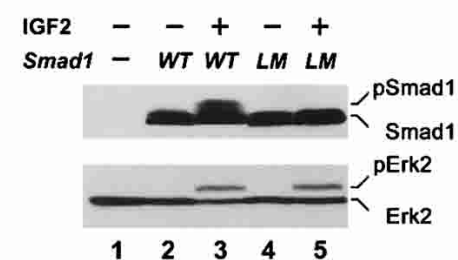

C
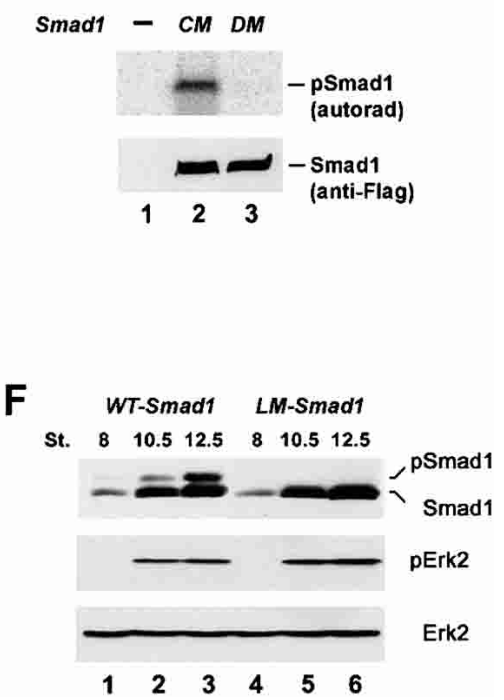

Figure 4. FGF8 and IGF2 induce linker phosphorylation of Smad1 via MAPK in vivo. Proteins in cell lysates were analyzed by Western blot with antibodies against Flag (for Smad1) and Erk1/2. (A) FGF8 shifts the electrophoretic mobility of WT-Smad1 (lane 4), but not of LM-Smad1 (lane 6). NIH3T3 cells were transfected with Flag-tagged Smad1 constructs, serum-starved for $6 \mathrm{~h}$, and recombinant mouse FGF8b protein (100 $\mathrm{ng} / \mathrm{mL}$ ) added for $10 \mathrm{~min}$. (B) Pre-incubation of NIH3T3 cells with the MEK1 inhibitor U0126 (20 $\mu \mathrm{M}) 1 \mathrm{~h}$ before the addition of FGF8 suppresses the phosphorylation of Smad1 and Erk1/2 (lane 4). (C) in vivo ${ }^{32} \mathrm{P}$ incorporation into the linker MAPK sites of Smad1 in Xenopus. Animal caps from uninjected embryos, injected with $C M$-Smad1 or DM-Smad1 were explanted at late blastula stage and incubated with $2 \mathrm{mCi} / \mathrm{mL}{ }^{32} \mathrm{P}$ orthophosphate for $45 \mathrm{~min}$. (D) Xenopus embryos injected first with $400 \mathrm{pg}$ Smad1 mRNA into each animal blastomere at the 8-cell stage, then with $40 \mathrm{nl}$ FGF8 protein (1.4 ng) into the blastocoele at stage 8 and lysed 30 min later. FGF8 induces phosphorylation of Erk2 and WT-Smad1, but not of LM-Smad1 (lanes 3,5). Erk1 is not expressed in the early Xenopus embryo (Chesnel et al. 1997). (E) Xenopus oocytes at stages V-VI were injected with $4 \mathrm{ng}$ Smad1 mRNA and $12 \mathrm{~h}$ later exposed to $18 \mathrm{ng} / \mathrm{mL}$ recombinant human IGF2 protein for $14 \mathrm{~h}$. IGF2 induced phosphorylation of WT-Smad1 and Erk2. $(F)$ Endogenous signals phosphorylate Smad1 linker region in Xenopus embryos. Equal numbers of Smad1 mRNA-injected embryos were lysed at mid-blastula (stage 8), early gastrula (stage 10.5), and late gastrula (stage 12.5), and protein extracts were analyzed by Western blot with antibodies against Erk, phosphorylated Erk (pErk), and Flag (for Smad1). Note the mobility shift of WT-Smad1 (lanes 2,3) but not LM-Smadl (lanes 5,6) in samples with high levels of phosphorylated Erk.

tant physiological implications. In vivo, Smad1 transcription factor activity results not only from BMP signaling through BMPR as currently thought, but from a combination of high BMPR activity and low RTK/MAPK signaling. In the case of ectodermal differentiation, the antineural effects of Smad1 will manifest themselves in regions of low BMP antagonists, high BMP, and low levels of signals that activate RTKs and act through MAPK. Presumably it takes multiple signals to achieve the low levels of Smad1 activity required to form the neural plate in embryonic ectoderm.

The demonstration that FGF and IGF can induce an inhibitory phosphorylation of Smad1 in vivo may also shed light on other aspects of vertebrate development. During organogenesis there are many instances in which the activities of the FGF and BMP pathways have opposing effects. These include FGF4 and BMP2 in the limb bud (Niswander and Martin 1993), FGF10 and BMP4 in lung morphogenesis (Weaver et al. 2000), FGF2 and BMP4 in cranial suture fusion (Warren et al. 2003), and FGF8 and BMP4 in the initiation of tooth development (Thesleff and Mikkola 2002). These developmental processes may also involve signal integration at the level of Smad1 by the molecular mechanism proposed in the present study on neural induction.

\section{Materials and methods}

DNA constructs, morpholino oligonucleotides, and synthetic mRNAs For mRNA injections we subcloned the amino-terminal Flag-tag and open reading frame of human Smad1 into pCS2, using pCMV5/FlagSmad1, pCMV5/Flag-Smad1-4SP/AP, and pCMV5/Flag-Smad1-4SP/APAAVA (an invaluable gift from J. Massagué, Sloan Kettering Cancer Center, New York) to generate WT-Smad1, LM-Smad1, and DM-Smad1, respectively. The fact that the biochemical properties of these proteins had been fully characterized (Kretzschmar et al. 1997) was essential for the execution of this study. CM-Smad1 was generated by exchanging an EcoRI/XbaI restriction fragment from DM-Smad1 into WT-Smad1. The antisense IGFR morpholino oligonucleotide (Gene Tools) was described in Richard-Parpaillon et al. (2002). To prepare sense mRNA, pCS2 constructs of WT-Smad1, LM-Smad1, DM-Smad1, CM-Smad1, chordin, xIGF2, xFGF8 (gift from J. Slack, University of Bath, UK), BMP7, and $D N-I G F R$ were linearized with NotI and transcribed with SP6 RNA polymerase. DN-FGFR 4a mRNA was synthesized from pSP64T (SalI digestion and SP6 transcription, gift from H. Okamoto, AIST Institute, Japan) and nlacZ mRNA from pXEXßgal (XbaI digestion and $\mathrm{T} 7$ transcription, gift from R. Harland, University of California, Berkeley).

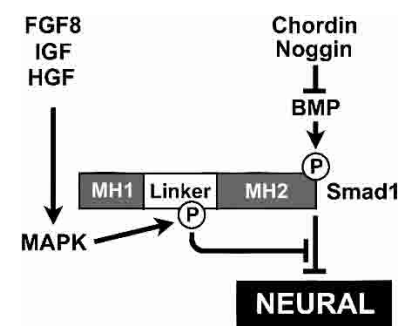

Figure 5. Model of the integration of multiple signaling pathways at the level of Smad1 phosphorylation in neural induction. MH1 and MH2 are evolutionarily conserved Mad-homology domains. Diagram modified from Kretzschmar et al. (1997). 
Embryo and oocyte manipulations

In vitro fertilization, embryo and explant culture, lineage tracing, RTPCR, and in situ hybridization were as reported (Pera et al. 2001). Xenopus embryos at the blastula stage were injected into the blastocoele cavity with $40 \mathrm{nl}$ protein solution of $0.1 \%$ bovine serum albumin (BSA) alone or together with recombinant mouse Chordin, human IGF2, mouse FGF8b (all from R\&D Systems) in 0.1× Barth medium. Manually defolliculated Xenopus oocytes (stages V-VI) were incubated with IGF2 protein in $0.1 \%$ BSA/OR-2 medium at $16^{\circ} \mathrm{C}$ as described (Chesnel et al. 1997).

Western blot analysis

Embryo, oocyte, or cell lysates were prepared using RIPA buffer $10.1 \%$ NP-40, $20 \mathrm{mM}$ Tris, pH 8.0, $1 \mathrm{mM}$ EDTA, 10\% Glycerol, proteinase inhibitor cocktail [Roche], $1 \mathrm{mM}$ sodium orthovanadate, $1 \mathrm{mM}$ PMSF). Proteins were separated by $12 \%$ SDS-PAGE (acrylamide:bisacrylamide $=$ 30:0.18) to resolve phosphorylated forms (Chesnel et al. 1997). Western blots were performed using antibodies against Flag (for Smad1, 1:2000, Sigma) and Erk1/2 (1:1000, Cell Signaling) and phospho-Erk1/2 (1:1000, Sigma). For radioactive labeling of Smad phosphorylation, Xenopus embryos were injected with $1 \mathrm{ng} C M$ - or DM-Smad1 mRNA at the four-cell stage and animal caps explanted at stage 9.5. The explants were cultured for $45 \mathrm{~min}$ in the presence of $2 \mathrm{mCi} / \mathrm{mL}\left[\gamma-\mathrm{P}^{32}\right]$ orthophosphate and lysed in RIPA buffer. Smadl was immunoprecipitated from the lysates and run on an SDS-PAGE gel. The amount of immunoprecipitated Smadl was quantified by Western blot, and the incorporation of radioactive phosphate was visualized by autoradiography.

\section{Acknowledgments}

We thank J. Massagué, H. Okamoto, J. Slack, and R. Harland for gifts of DNA constructs; Y. Sun for advice, Z. Unno for in situ hybridizations; S. L. Zipursky, Y. Sun, G. Weinmaster, K. McLaren, M. Kessel, O. Wessely, and C. Coffinier for comments on the manuscript; A. Cuellar for technical assistance; and A. De Robertis for secretarial help. E.M.P was an HFSPO fellow. This work was supported by NIH grant HD-21502-17. E.M.D.R is a Howard Hughes Medical Institute Investigator.

The publication costs of this article were defrayed in part by payment of page charges. This article must therefore be hereby marked "advertisement" in accordance with 18 USC section 1734 solely to indicate this fact.

\section{Note added in proof}

While this work was under review, Sater et al. (2003) reported that mutations in the MAPK sites of Xenopus Smadl caused hyperventralizing effects in microinjected embryos. The results of Sater et al. (2003) and those of the present study complement each other, supporting a role for linker phosphorylation of Smadl in neural induction.

\section{References}

Blume-Jensen, P. and Hunter, T. 2001. Oncogenic kinase signalling. Nature 411: 355-365.

Chesnel, F., Bonnec, G., Tardivel, A., and Boujard, D. 1997. Comparative effects of insulin on the activation of the Raf/Mos-dependent MAP kinase cascade in vitellogenic versus postvitellogenic Xenopus oocytes. Dev. Biol. 188: 122-133.

Christen, B. and Slack, J.M.W. 1997. FGF-8 is associated with anteroposterior patterning and limb regeneration in Xenopus. Dev. Biol. 192: 455-466.

Collavin, L. and Kirschner, M.W. 2003. The secreted Frizzled-related protein Sizzled functions as a negative feedback regulator of extreme ventral mesoderm. Development 130: 805-816.

Cooke, J. and Smith, J.C. 1989. Gastrulation and larval pattern in Xenopus after blastocoelic injection of a Xenopus-derived inducing factor: Experiments testing models for the normal organization of mesoderm. Dev. Biol. 131: 383-400.

De Robertis, E.M., Larraín, J., Oelgeschläger, M., and Wessely, O. 2000. The establishment of Spemann's organizer and patterning of the vertebrate embryo. Nat. Rev. Genet. 1: 171-181.

Grimm, O.H. and Gurdon, J.B. 2002. Nuclear exclusion of Smad2 is a mechanism leading to loss of competence. Nat. Cell Biol. 4: 519-522.

Hardcastle, Z., Chalmers, A.D., and Papalopulu, N. 2000. FGF-8 stimulates neuronal differentiation through FGFR-4a and interferes with mesoderm induction in Xenopus embryos. Curr. Biol. 10: 1511-1514.

Harland, R. 2000. Neural induction. Curr. Opin. Genet. Dev. 10: 357362.

Hongo, I., Kengaku, M., and Okamoto, H. 1999. FGF signaling and the anterior neural induction in Xenopus. Dev. Biol. 216: 561-581.

Kretzschmar, M., Doody, J., and Massagué, J. 1997. Opposing BMP and EGF signalling pathways converge on the TGF- $\beta$ family mediator Smad1. Nature 389: 618-622.

Kretzschmar, M., Doody, J., Timokhina, I., and Massague, J. 1999. A mechanism of repression of TGF / Smad signaling by oncogenic Ras. Genes \& Dev. 13: 804-816.

Lamb, T.M. and Harland, R.M. 1995. Fibroblast growth factor is a direct neural inducer, which combined with noggin generates anterior-posterior neural pattern. Development 121: 3627-3636.

Massagué, J. and Chen, Y.-G. 2000. Controlling TGF- $\beta$ signaling. Genes \& Dev. 14: 627-644.

Nguyen, V.H., Trout, J., Connors, S.A., Andermann, P., Weinberg, E., and Mullins, M.C. 2000. Dorsal and intermediate neuronal cell types of the spinal cord are established by a BMP signaling pathway. Development 127: 1209-1220.

Niswander, L. and Martin, G.R. 1993. FGF-4 and BMP-2 have opposite effects on limb growth. Nature 361: $68-71$.

Pera, E.M., Wessely, O., Li, S.-Y., and De Robertis, E.M. 2001. Neural and head induction by insulin-like growth factor signals. Dev. Cell 1: 655-665.

Richard-Parpaillon, L., Héligon, C., Chesnel, F., Boujard, D., and Philpott, A. 2002. The IGF pathway regulates head formation by inhibiting Wnt signaling in Xenopus. Dev. Biol. 244: 407-417.

Sater, A.K., El-Hodiri, H.M., Goswami, M., Alexander, T.B., Al-Sheikh, O., Etkin, L.D., and Akif Uzman, J. 2003. Evidence for antagonism of BMP-4 signals by MAP kinase during Xenopus axis determination and neural specification. Differentiation 71: 434-444.

Schohl, A. and Fagotto, F. 2002. $\beta$-catenin, MAPK and Smad signaling during early Xenopus development. Development 129: 37-52.

Spemann, H. 1938. Embryonic development and induction. Yale University Press, New Haven, CT.

Stern, C.D. 2002. Induction and initial patterning of the nervous system-The chick embryo enters the scene. Curr. Opin. Genet. Dev. 12: $447-451$.

Streit, A., Stern, C.D., Thery, C., Ireland, G.W., Aparicio, S., Sharpe, M.J., and Gherardi, E. 1995. A role for HGF/SF in neural induction and its expression in Hensen's node during gastrulation. Development. 121: 813-824.

Streit, A., Sockanathan, S., Perez, L., Rex, M., Scotting, P.J., Sharpe, P.T., Lovell-Badge, R., and Stern, C.D. 1997. Preventing the loss of competence for neural induction: HGF/SF, L5 and Sox-2. Development 124: $1191-1202$

Streit, A., Berliner, A.J., Papanayotou, C., Sirulnik, A., and Stern, C.D. 2000. Initiation of neural induction by FGF signalling before gastrulation. Nature 406: 74-78.

Thesleff, I. and Mikkola, M. 2002. The role of growth factors in tooth development. Int. Rev. Cytol. 217: 93-135.

Warren, S.M., Brunet, L.J., Harland, R.M., Economides, A.N., and Longaker, M.T. 2003. The BMP antagonist noggin regulates cranial suture fusion. Nature 422: 625-629.

Weaver, M., Dunn, N.R., and Hogan, B.L.M. 2000. Bmp4 and Fgf10 play opposing roles during lung bud morphogenesis. Development 127: 2695-2704.

Weinstein, D.C. and Hemmati-Brivanlou, A. 1999. Neural induction. Annu. Rev. Cell Dev. Biol. 15: 411-433.

Wilson, S.I. and Edlund, T. 2001. Neural induction: Toward a unifying mechanism. Nat. Neurosci. 4: 1161-1168.

Wilson, S.I., Graziano, E., Harland, R., Jessell, T.M., and Edlund, T. 2000 An early requirement for FGF signalling in the acquisition of neural cell fate in the chick embryo. Curr. Biol. 10: 421-429. 


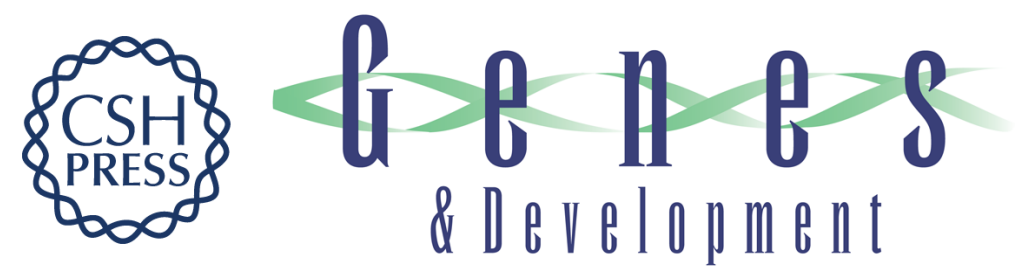

\section{Integration of IGF, FGF, and anti-BMP signals via Smad1 phosphorylation in neural induction}

Edgar M. Pera, Atsushi Ikeda, Edward Eivers, et al.

Genes Dev. 2003, 17:

Access the most recent version at doi:10.1101/gad.1153603

References This article cites 29 articles, 9 of which can be accessed free at: http://genesdev.cshlp.org/content/17/24/3023.full.html\#ref-list-1

License

Email Alerting

Receive free email alerts when new articles cite this article - sign up in the box at the top Service right corner of the article or click here.

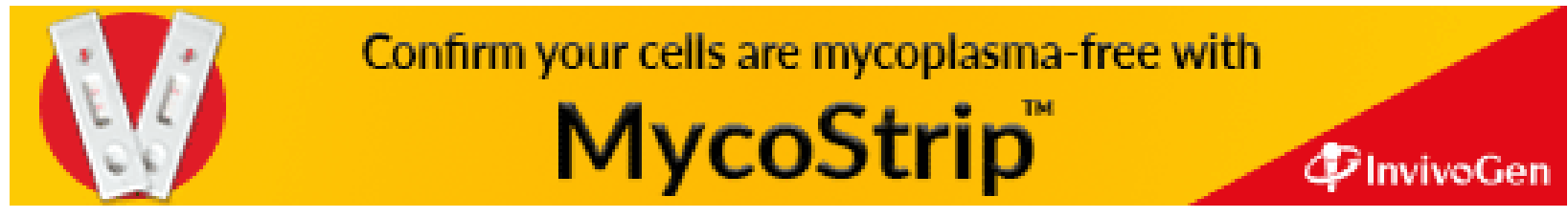

